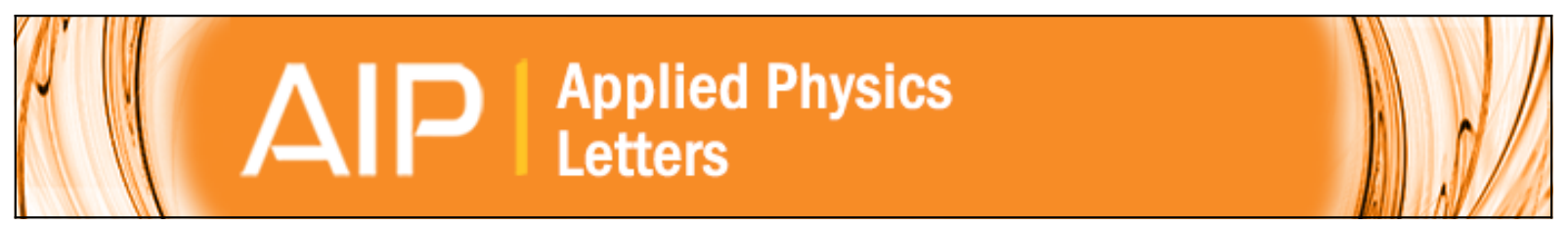

Influence of deep defects on device performance of thin-film polycrystalline silicon solar cells

M. Fehr, P. Simon, T. Sontheimer, C. Leendertz, B. Gorka, A. Schnegg, B. Rech, and K. Lips

Citation: Applied Physics Letters 101, 123904 (2012); doi: 10.1063/1.4754609

View online: http://dx.doi.org/10.1063/1.4754609

View Table of Contents: http://scitation.aip.org/content/aip/journal/apl/101/12?ver=pdfcov

Published by the AIP Publishing 


\title{
Influence of deep defects on device performance of thin-film polycrystalline silicon solar cells
}

\author{
M. Fehr, ${ }^{\text {a) }}$ P. Simon, T. Sontheimer, C. Leendertz, B. Gorka, A. Schnegg, B. Rech, \\ and K. Lips \\ Helmholtz-Zentrum Berlin für Materialien und Energie, Institut für Silizium-Photovoltaik, \\ Kekuléstr. 5, 12489 Berlin, Germany
}

(Received 29 June 2012; accepted 6 September 2012; published online 21 September 2012)

\begin{abstract}
Employing quantitative electron-paramagnetic resonance analysis and numerical simulations, we investigate the performance of thin-film polycrystalline silicon solar cells as a function of defect density. We find that the open-circuit voltage is correlated to the density of defects, which we assign to coordination defects at grain boundaries and in dislocation cores. Numerical device simulations confirm the observed correlation and indicate that the device performance is limited by deep defects in the absorber bulk. Analyzing the defect density as a function of grain size indicates a high concentration of intra-grain defects. For large grains $(>2 \mu \mathrm{m})$, we find that intra-grain defects dominate over grain boundary defects and limit the solar cell performance. (c) 2012 American Institute of Physics. [http://dx.doi.org/10.1063/1.4754609]
\end{abstract}

The preparation of thin-film polycrystalline silicon (poly-Si) solar cells on glass by the crystallization of amorphous $\mathrm{Si}$ is a promising alternative to conventional waferbased Si solar cells. ${ }^{1-5}$ In particular, high-rate $(600 \mathrm{~nm} / \mathrm{min})$ electron beam (e-beam) evaporation of $\mathrm{Si}$ is a fast and costeffective method to produce high-quality poly-Si solar cells. It has been demonstrated that poly-Si mini-modules with efficiencies of $7.8 \%$ can be prepared by combining high-rate e-beam evaporation with solid-phase crystallization (SPC), hydrogen plasma passivation (HP), and rapid-thermal annealing (RTA) post deposition treatments. ${ }^{6-8}$ However, it was shown that the open-circuit voltage $\left(V_{\text {oc }}\right)$ is limited to $485 \mathrm{mV}$ (Ref. 7) and is therefore significantly lower compared to wafer-based $\mathrm{Si}$ solar cells, which reach a $V_{\mathrm{oc}}$ of $650 \mathrm{mV}$ for multicrystalline $\mathrm{Si}$ solar cells, ${ }^{9} 706 \mathrm{mV}$ for monocrystalline Si solar cells with a homojunction, ${ }^{9-11}$ and $745 \mathrm{mV}$ in the case of monocrystalline Si solar cells with a heterojunction. ${ }^{12}$ In order to further enhance the performance of poly-Si solar cells, mechanisms limiting $V_{\mathrm{oc}}$ have to be identified. Several reasons for a limitation of $V_{\mathrm{oc}}$ are currently discussed. It has been shown that disordered grain boundaries in poly-Si are electrically active as they carry a large amount of deep defects which were attributed to paramagnetic dangling-bond (DB) defects. ${ }^{13,14}$ Wong et al. ${ }^{15,16}$ discussed the influence of dislocations acting as shallow traps. Coordination defects or vacancies at dislocations and structural defects within crystalline grains (intra-grain defects) are further potential candidates for recombination centers. ${ }^{6}$ It is likely that during growth or post-deposition treatments (e.g., by RTA), impurities are introduced into the absorber layer, which are known to limit the electronic quality of crystalline Si solar cells. ${ }^{17}$ Recombination at interfaces of the absorber layer with adjacent emitter layers or SiN diffusion barriers have to be considered as well. Finally, post-deposition HP treatments are also known to introduce structural defects in crystalline Si (e.g., H platelets). ${ }^{18}$

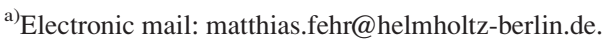

In order to distinguish between the above-mentioned possibilities and to find the dominating source of device efficiency limitation, we present quantitative electron-paramagnetic resonance (EPR) measurements in combination with numerical device simulations showing that $V_{\text {oc }}$ of poly-Si solar cells based on e-beam evaporation is limited by paramagnetic defects in the absorber bulk, which we assign to deep coordination defects. By varying grain size, we evaluate the presence of grain boundary and intra-grain defects and their influence on the electronic properties. We conclude that paramagnetic defects in the bulk of the absorber layer, such as DBs at grain boundaries or in dislocation cores, are the most important limitation of the performance of poly-Si solar cells.

Poly-Si solar cells were prepared by e-beam evaporation of $\mathrm{Si}$ at a substrate temperature of $T_{\mathrm{s}}=200-600^{\circ} \mathrm{C}$ and consist of emitter, absorber, and back-surface field as reported in Ref. 7 (structure shown in Fig. 1(a)). For details about solar cells and post-deposition treatments (SPC, RTA, and HP), see Refs. 19 and 20. $V_{\text {oc }}$ was measured in a conventional sun simulator under standard test conditions (AM1.5, $100 \mathrm{~mW} / \mathrm{cm}^{2}$ at $25^{\circ} \mathrm{C}$ ). The defect density in the absorber layer was determined by EPR. For this purpose, we deposited $\mathrm{p}^{-}$absorber layers on Corning 1737 glass (Corning, Inc., NY, USA) or on SiN coated BOROFLOAT glass (SCHOTT AG, Mainz, Germany), omitting n- and p-type layers (see Fig. 1(b)). Background EPR signals from the glass substrate were avoided by removing the layer from the substrate using wet-chemical etching (diluted HF) (see Fig. 1(b)). The grain size was determined by Electron backscatter diffraction (EBSD) measurements or a Secco etch in combination with scanning electron microscopy (SEM) (for details see Ref. 6).

Continuous wave (c.w.) EPR experiments were carried out at a microwave frequency of $9.8 \mathrm{GHz}$ (X Band) on a commercial BRUKER ELEXSYS E580 spectrometer using a $\mathrm{TE}_{011}$ super high $\mathrm{Q}$ microwave resonator. The density of defects was determined by a calibrated spin-counting procedure. Details about EPR measurements and sample preparation can be found in the supplementary material. ${ }^{20}$ 
(a) Solar cell structure

\begin{tabular}{|c|}
\hline poly-Si $\left(\mathrm{p}^{+}\right)$ \\
\hline poly-Si ( $\left.p^{-}\right)$ \\
\hline poly-Si $\left(n^{+}\right)$ \\
\hline $\mathrm{SiN}$ \\
\hline glass substrate \\
\hline
\end{tabular}

(b) EPR sample structure

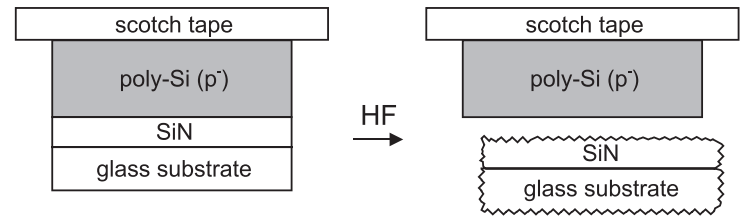

FIG. 1. (a) Schematic of poly-Si solar cell structure. (b) EPR sample structure and procedure to release poly-Si layer from substrate by wet-chemical etching (diluted HF). The poly-Si layer is supported by a scotch tape.

The inset in Fig. 2 shows the c.w. EPR spectrum of a SPC treated poly-Si absorber layer. We evaluated a $g$ value at the zero-crossing of $g=2.0048$ (4) and a peak-to-peak width of $\Delta B_{\mathrm{pp}}=0.8(1) \mathrm{mT}$. These values are typical for all samples investigated in this contribution. $g$ values range from 2.0040 to 2.0050 , and $\Delta B_{\text {pp }}$ typically lies in the range of $0.7-0.9 \mathrm{mT}$. The fact that the $g$ values are not equal to $2.0055(5)$ as it is

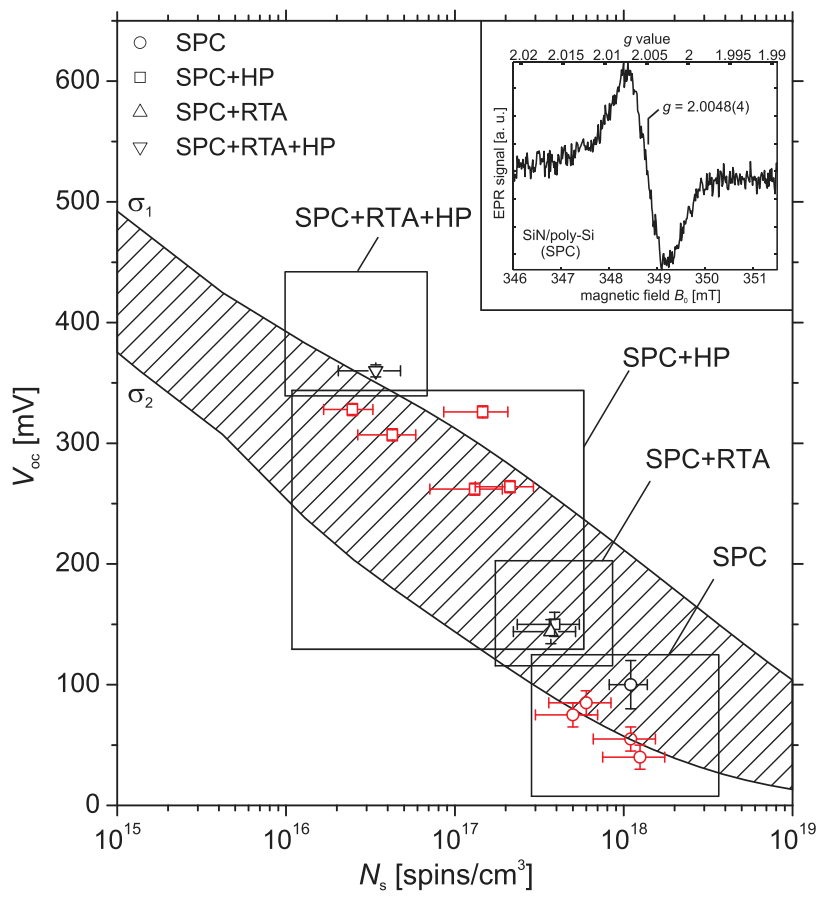

FIG. 2. Experimental (open symbols) and theoretical results (solid lines) of $V_{\mathrm{oc}}$ of poly-Si solar cells as a function of defect density in the poly-Si absorber bulk. Red (grey) symbols indicate samples on Corning 1737 or thermally oxidized Si wafers, and black symbols are samples deposited on SiN-coated BOROFLOAT glass. Solid lines show numerical device simulations of $V_{\mathrm{oc}}$ as a function of the density of neutral defects. $\sigma_{1}=$ $10^{-15} / 10^{-16} \mathrm{~cm}^{2}$ and $\sigma_{2}=10^{-14} / 10^{-14} \mathrm{~cm}^{2}$ indicate capture cross-sections of defects used for simulations. The shaded area marks the area between the two simulations. The inset shows an EPR spectrum of a poly-Si absorber layer after SPC and lift-off from the SiN-coated glass substrate. usually found for deep defects at grain boundaries in poly-Si materials ${ }^{13,14}$ already indicates that defects observed in the present type of material differ from grain boundary defects. For the SPC treated poly-Si absorber layer, we evaluated a defect density of $1.1( \pm 0.3) \times 10^{18} \mathrm{~cm}^{-3}$, and the $V_{\mathrm{oc}}$ of the corresponding solar cell is $100(20) \mathrm{mV}$.

In order to further study the dependence of $V_{\text {oc }}$ on defect density, we adjusted the electronic quality of the absorber material by a systematic variation of the post-deposition treatments. We applied either SPC, SPC and RTA, SPC and HP, as well as a combined SPC, HP, and RTA post-deposition treatment. Results of all samples after post-deposition treatments are shown in Fig. 2, which plots $V_{\mathrm{oc}}$ as a function of defect density. We see that after SPC, the EPR defect density is high $\left(\approx 10^{18} \mathrm{~cm}^{-3}\right)$ and the corresponding $V_{\mathrm{oc}}$ value does not exceed $100 \mathrm{mV}$. Applying an additional RTA step only slightly improves the electronic quality (defect density: $\approx 4 \times 10^{17} \mathrm{~cm}^{-3}, V_{\mathrm{oc}}=140 \mathrm{mV}$ ). In contrast, HP after SPC or a combined SPC, HP, and RTA treatment decreases the defect density by about one order of magnitude, increasing $V_{\text {oc }}$ up to $360 \mathrm{mV}$. Fig. 2 clearly shows that an increase in $V_{\text {oc }}$ is correlated to a decrease of the defect density, indicating that $V_{\text {oc }}$ is limited by paramagnetic defects.

To gain deeper insight into the observed correlation and to determine to which extent $V_{\mathrm{oc}}$ is limited by the observed paramagnetic defects, we carried out numerical device simulations calculating $V_{\mathrm{oc}}$ as a function of defect density using AFORS-HET, ${ }^{21}$ a numerical solar cell simulation package. Simulations were performed on the above mentioned solar cell structure assuming a Gaussian distribution of DB defects centered in the middle of the band gap. The amphoteric nature of the DB defect was approximated by two states at different energy levels using the Shockley-Read-Hall theory. ${ }^{22}$ Since EPR is only sensitive to paramagnetic defects, we calculated the spin density $N_{\mathrm{s}}$ by extracting the density of neutral DBs. Simulations of $V_{\mathrm{oc}}$ assume AM1.5 illumination, while $N_{\mathrm{s}}$ is calculated with dark conditions. Since precise values for capture cross-sections of DB defects are still a matter of debate in literature and range between $10^{-14}$ and $10^{-17} \mathrm{~cm}^{2}$ (see Refs. 23-26), we performed two simulations which result in the upper and lower solid lines in Fig. 2. The upper solid line shows simulations of $V_{\text {oc }}$ using capture cross-sections of $10^{-15} / 10^{-16} \mathrm{~cm}^{2}$ for the two energy level and the lower solid line corresponds to capture crosssections of $10^{-14} \mathrm{~cm}^{2}$ for both levels. The experimental data lie within the area spanned by the two capture cross-section scenarios and trends are reproduced by the numerical simulation. We can therefore conclude that the defect density is an important factor in limiting the device performance of poly$\mathrm{Si}$ solar cells within the device quality range investigated in this study.

Having shown that paramagnetic defects are limiting the device performance of poly-Si solar cells, we now discuss the microscopic origin of the observed defects. There is a general consensus in literature that paramagnetic states in poly-Si with $g \approx 2.0055$ can be attributed to DB defects at disordered grain boundaries. ${ }^{13}$ If this was indeed the case, we would expect an inverse proportionality between the total defect density $\left(N_{\text {tot }}\right)$ and the grain size. Assuming cubic grains, we obtain $N_{\text {tot }}=\frac{3 N_{\mathrm{A}}}{a}$, where $N_{\mathrm{A}}$ is the defect density 


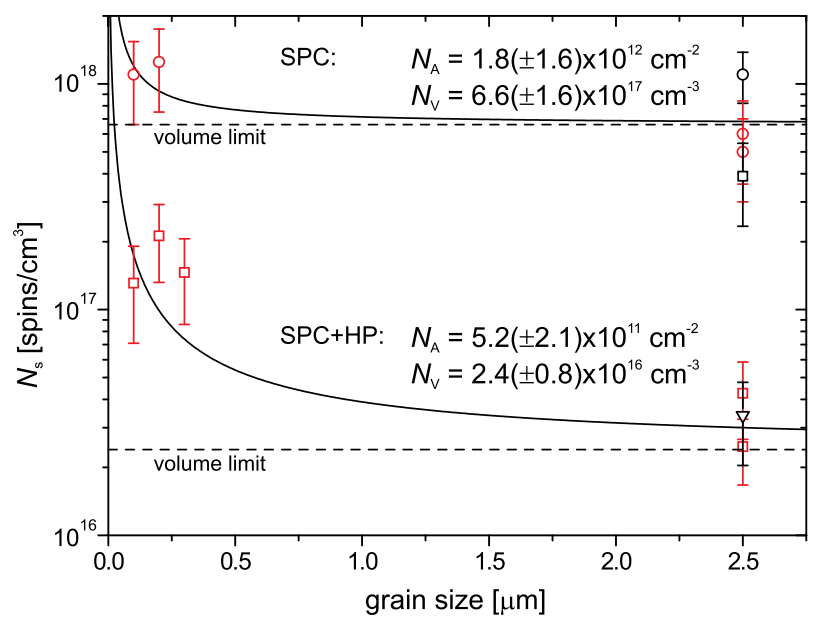

FIG. 3. Defect density in poly-Si as a function of grain size after SPC and SPC + HP (for symbol and color code see Fig. 2). Solid lines are model calculations of the defect density assuming defects at grain boundaries (with density $N_{\mathrm{A}}$ ) and inside grains (with density $N_{\mathrm{V}}$ ). Standard errors of fit parameters are given in brackets. The dashed line indicates the lower limit for the defect density $\left(N_{\mathrm{V}}\right)$ in case of infinite grain size.

per unit grain boundary area and $a$ denotes the grain size. Fig. 3 plots the defect density of SPC and SPC + HP treated samples as a function of grain size. In both cases, the defect density of small grained samples $(200-300 \mathrm{~nm})$ is only about a factor of 2-3 larger than in poly-Si samples with a large grain size of $2.5 \mu \mathrm{m}$. If the measured EPR signal were solely due to defects at grain boundaries and the density of defects at grain surfaces did not vary largely, we would expect about a factor of 10 less defects in samples with larger grain size. As this is not observed, our measurements suggest that the interior of grains host a large number of defects. Since the experimental data in Fig. 3 cannot be explained with grain boundary defects alone, we have to include volume (intragrain) defects in our model: $N_{\text {tot }}=\frac{3 N_{\mathrm{A}}}{a}+N_{\mathrm{V}}$, where $N_{\mathrm{V}}$ denotes the density of intra-grain defects. Results of fitting this equation to the experimental data are shown in Fig. 3 together with fit parameters $N_{\mathrm{A}, \mathrm{V}}$ and their errors. Deviations of the modeled curves from the data points and the large error of $N_{\mathrm{A}}$ are ascribed to the fact that the present model is highly idealized. Simulations of grain boundary defects $\left(N_{\mathrm{A}}\right)$ would require a much more sophisticated model considering distributions in grain size and shape. Although we have only two regimes of grain size and apply an idealized model, the general trend indicates that the density of intra-grain defects, represented by $N_{\mathrm{V}}$, is high in all cases and dominates over grain-boundary associated defects, represented by $N_{\mathrm{A}}$, in case of a large grain size of $2.5 \mu \mathrm{m}$. This finding indicates that further increasing the grain size beyond $2.5 \mu \mathrm{m}$ will not lead to a major reduction in total defect density, as the volume limit (given by $N_{\mathrm{V}}$, dashed lines in Fig. 3) is already reached at a grain size of $2.5 \mu \mathrm{m}$. Hence, it is important to further elucidate the microscopic origin of intra-grain defects as they contribute majorly to the total defect density. There are several indications that defects are linked to structural intra-grain defects. Detailed SEM investigations of defectetched poly-Si samples showed, for example, a clear signature of etch pits related to intra-grain defects. ${ }^{6,20}$ In addition, Mchedlidze et al. $^{27,28}$ showed that well-known D1-D4 photoluminescence lines of plastically deformed single- crystalline silicon ${ }^{29}$ are present in poly-Si materials indicating a large density of dislocations. DB defects associated with dislocations in plastically deformed $\mathrm{Si}$ were detected by EPR in a variety of studies. ${ }^{30,31}$ They exhibit EPR spectra with principal $g$ values between 2.002 to 2.009 , which match $g$ values observed in our study. It is therefore reasonable to assign intra-grain defects to deep coordination defects in dislocation cores.

In summary, we performed quantitative EPR measurements on e-beam deposited and solid-phase crystallized poly-Si and correlated our results to $V_{\mathrm{oc}}$ measurements of corresponding solar cells. Using a microwave cavity with a high Q factor increased the EPR sensitivity and allowed us to determine defect densities as low as $\approx 2 \times 10^{16} \mathrm{~cm}^{-3}$ in single thin $(1 \mu \mathrm{m})$ poly-Si absorber layers. Our measurements show a correlation between device performance $\left(V_{\text {oc }}\right)$ and defect density. Complementing experimental data with numerical device simulations allows us to conclude that paramagnetic deep defects are dominating device performance. Evaluating the defect density as a function of grain size indicates that the majority of deep defects are intra-grain defects, which we assign to deep defects in dislocation cores. Hence, in large-grained poly-Si, a further increase of grain size will not result in a major decline of the total defect density and an improvement in solar cell performance. As a major challenge in poly-Si solar cell development, we define improvement of intra-grain crystal structure.

We thank R. J. Egan for providing SiN-coated glass substrates and C. Klimm (HZB) for EBSD measurements. Financial support from BMBF (EPR-Solar network project 03SF0328) is acknowledged.

${ }^{1}$ T. Matsuyama, N. Terada, T. Baba, T. Sawada, S. Tsuge, K. Wakisaka, and S. Tsuda, J. Non-Cryst. Solids 198, 940 (1996).

${ }^{2}$ M. A. Green, P. A. Basore, N. Chang, D. Clugston, R. Egan, R. Evans, D. Hogg, S. Jarnason, M. Keevers, P. Lasswell, J. O'Sullivan, U. Schubert, A. Turner, S. R. Wenham, and T. Young, Sol. Energy 77, 857 (2004).

${ }^{3}$ M. J. Keevers, T. L. Young, U. Schubert, and M. A. Green, in Proceedings of the 22nd European Photovoltaics Solar Energy Conference, Milan, Italy, 2007 (unpublished), p. 1783.

${ }^{4}$ I. Gordon, L. Carnel, D. Van Gestel, G. Beaucarne, and J. Poortmans, Prog. Photovoltaics 15, 575 (2007).

${ }^{5}$ A. G. Aberle, J. Cryst. Growth 287, 386 (2006).

${ }^{6}$ C. Becker, F. Ruske, T. Sontheimer, B. Gorka, U. Bloeck, S. Gall, and B. Rech, J. Appl. Phys. 106, 084506 (2009).

${ }^{7}$ T. Sontheimer, C. Becker, F. Ruske, C. Klimm, U. Bloeck, S. Gall, O. Kunz, T. Young, R. Egan, J. Hupkes, and B. Rech, in 35th IEEE Photovoltaic Specialists Conference (IEEE, 2010), p. 614.

${ }^{8}$ T. Sontheimer, S. Scherf, C. Klimm, C. Becker, and B. Rech, J. Appl. Phys. 110, 063530 (2011).

${ }^{9}$ M. A. Green, K. Emery, Y. Hishikawa, W. Warta, and E. D. Dunlop, Prog. Photovoltaics 20, 12 (2012).

${ }^{10}$ J. Zhao, A. H. Wang, M. A. Green, and F. Ferrazza, Appl. Phys. Lett. 73, $1991(1998)$

${ }^{11}$ J. Zhao, Sol. Energy Mater. Sol. Cells 82, 53 (2004).

${ }^{12}$ T. Mishima, M. Taguchi, H. Sakata, and E. Maruyama, Sol. Energy Mater. Sol. Cells 95, 18 (2011).

${ }^{13}$ N. M. Johnson, D. K. Biegelsen, and M. D. Moyer, Appl. Phys. Lett. 40, 882 (1982).

${ }^{14}$ N. H. Nickel, G. B. Anderson, and R. I. Johnson, Phys. Rev. B 56, 12065 (1997).

${ }^{15}$ J. Wong, J. L. Huang, B. Eggleston, M. A. Green, O. Kunz, R. Evans, M. Keevers, and R. J. Egan, J. Appl. Phys. 107, 123705 (2010).

${ }^{16}$ J. Wong, J. Huang, S. Varlamov, M. A. Green, and M. Keevers, "The roles of shallow and deep levels in the recombination behavior of 
polycrystalline silicon on glass solar cells," Prog. Photovolt: Res. Appl. (unpublished).

${ }^{17}$ J. R. Davis, A. Rohatgi, R. H. Hopkins, P. D. Blais, P. Rai-Choudhury, J. R. McCormick, and H. C. Mollenkopf, IEEE Trans. Electron Devices 27, 677 (1980).

${ }^{18}$ N. H. Nickel, G. B. Anderson, N. M. Johnson, and J. Walker, Phys. Rev. B 62, 8012 (2000).

${ }^{19}$ B. Gorka, B. Rau, P. Dogan, C. Becker, F. Ruske, S. Gall, and B. Rech, Plasma Processes Polym. 6, S36 (2009).

${ }^{20}$ See supplementary material at http://dx.doi.org/10.1063/1.4754609 for details about the sample preparation, quantitative EPR and for SEM images of defect-etched poly-Si samples.

${ }^{21}$ R. Stangl and C. Leendertz, Physics and Technology of AmorphousCrystalline Heterostructure Silicon Solar Cells (Springer-Verlag, 2011).
${ }^{22}$ S. Steingrube, R. Brendel, and P. P. Altermatt, Phys. Status Solidi A 209, 390 (2012).

${ }^{23}$ R. A. Street, Appl. Phys. Lett. 41, 1060 (1982).

${ }^{24}$ R. A. Street, J. Zesch, and M. J. Thompson, Appl. Phys. Lett. 43, 672 (1983).

${ }^{25}$ R. Meaudre and M. Meaudre, Philos. Mag. Lett. 82, 303 (2002).

${ }^{26}$ R. Meaudre and M. Meaudre, Appl. Phys. Lett. 85, 245 (2004).

${ }^{27}$ T. Mchedlidze, T. Arguirov, M. Holla, and M. Kittler, J. Appl. Phys. 105, 093107 (2009).

${ }^{28}$ T. Mchedlidze, J. Schneider, T. Arguirov, and M. Kittler, Phys. Status Solidi C 8, 1334 (2011).

${ }^{29}$ R. Sauer, J. Weber, J. Stolz, E. R. Weber, K. H. Kusters, and H. Alexander, Appl. Phys. A 36, 1 (1985).

${ }^{30}$ E. R. Weber and H. Alexander, J. Phys. (Paris) 40, C6-101 (1979).

${ }^{31}$ E. R. Weber and H. Alexander, J. Phys. (Paris) 44, C4-319 (1983). 